\title{
A satisfação sexual da mulher adulta
}

Sônia Helena Tlusty Furlanetto*

Oswaldo M. Rodrigues Jr.**

\section{RESUMO}

A satisfação sexual de mulheres adultas, embora seja considerada de importância no discurso das próprias mulheres e de suas parceiras sexuais e afetivas, pouco aparece no discurso científico e técnico da psicologia, e mais especificamente nos estudos da sexualidade no Brasil.

Os autores buscaram pesquisar as associações de mulheres sobre a cessação das necessidades sexuais, aqui denominada satisfação sexual.

Um questionário, desenvolvido a partir de um estudo piloto, foi aplicado a 110 mulheres adultas de 25 a 40 anos com parceria sexual fixa na área metropolitana de São Paulo.

Embora os resultados apenas apontem formas cognitivas através das quais as mulheres podem se referir à satisfação sexual, os resultados obtidos são os que necessitam ser considerados para a interação primária sobre o assunto em níveis profissionais.

* Acadêmica de Psicologia da Universidade de Guarulhos.

** Psicólogo Clínico e Terapeuta Sexual associado ao Instituto H. Ellis.

Recebido em 05.05.95

Aprovado em 0.06 .95 
O fato mais importante surgido foi a associação de orgasmo e satisfação social, atingindo $80 \%$ das pesquisas. O sentir-se atraída sexualmente pelo parceiro apareceu em $74 \%$ das paulistanas. Os parceiros carinhosos são importantes para a satisfação sexual em $66 \%$ das mulheres e as carícias dos parceiros para $61 \%$. As fantasias sexuais com o parceiro sexual ocorre em 50\% das Mulheres.

A satisfação sexual foi referida por $86 \%$ das Mulheres pesquisadas, destas $15 \%$ não estariam satisfeitas sexualmente sempre. Devemos considerar que apenas as mulheres que responderam o questionário estão sendo consideradas (64\%). Mesmo assim, surpreendem um nível alto de satisfação sexual entre as mulheres adultas de São Paulo.

\section{ABSTRACT}

Although adult female's sexual satisfaction in considered on importance in females and their partner's talking, it is not an issue of importance in scientific research among psychologists and sexologists in Brazil.

The authors searched to associate sexual satisfaction in adult metropolitan females from 25 to 40 years old with steady sexual partner. A questionary was developed from a pilot study and given to 110 women.

Results are understood as representatives of women cognitions through which they deal with reality, although may not be reality for all of them. So they shall be considered by health professionals dealing with human sexuality.

The most atonishing fact was that orgasm was associated to sexual satisfaction by $80 \%$ of the women. To feel sexually atracted by their partner was considered by $74 \%$ and caressing partners were important to $66 \%$ for their sexual satisfaction. The partners cares was pointed out as important for sexual satisfaction by $61 \%$ of the women and $50 \%$ refered sexual fantasies with their own partners to reach sexual satisfaction.

Reaching sexual satisfaction was refered by $86 \%$ of the women, although $15 \%$ of them were not sexually satisfied all the time. We have to consider the fact that only women that answered the questionary are studied (64\% of all questionaries given). Yet surprisingly there is a high level of sexual satisfaction among the women studied. 


\section{INTRODUÇÃO}

O interesse sobre a satisfação sexual de mulheres adultas surgiu das observações do cotidiano de outras Mulheres, quando algumas mulheres falam a respeito e outras se omitem.

A compreensão do sentido de satisfação foi buscada em várias facetas em dicionários gramaticais e dicionários técnicos em Psicologia para produzir a discussão e a apreciação da pesquisa que seria efetuada,

Satisfação é "Ato ou efeito de satisfazer; contentamento, alegria, aprazimento, agrado, cessação de um desejo, produzida pela posse do objeto desejado; sentimento de aprovação pela qual se repara uma ofensa; retratação; pagamento; indenização; satisfação de uma dúvida; conta que se dá de uma incumbência, desempenho; justificação pl. explicações do latim satisfação." (Fernandes, 1970)

Satisfação é o "Estado de um organismo quando as tendências dominantes motivação atingiram seu objetivo ou finalidade." Edward L. Thorndike, em The Psychology of Wants, Interests and Atitudes (1935), define satisfação como "o estado que o animal nada faz por evitar freqüentemente fazendo coisas que o mantenham ou renovem." (Cabral e Nick, 1974)

Satisfação é "Ação ou efeito de satisfazer, sentimento de aprovação, pagamento, desempenho, desculpa, explicações.” (Brasil Novo, 1979)

Hite (1986) afirma que embora a percepção sensorial e a atividade intelectual possam estar em ponto mínimo durante a atividade sexual, em geral há bastante compreensão conscientes da satisfação de modo a fornecer grande estímulo para a continuação da atividade via de regra até o orgasmo. Embora não estejam inteiramente esclarecidos. as fontes desta satisfação parecem ser influenciadas:

- pela natureza e a intensidade dos estímulos físicos e psicológicos que provoca a reação sexual;

- pela capacidade fisiológica inata do indivíduo que reage,

- pela capacidade psicológica e a do indivíduo, com sua capacidade de obter parceiros sexuais; desenvolver situações psicológicas eficazes durante a atividade manifesta e de reagir com simpatia à atividade do parceiro;

- pelo nível fisiológico que é atingido no organismo. É possível que o organismo, que é acompanhado por freqüência de pulso de 150, possa ser mais estimulante que o organismo alcançado com frequiência de pulso de 
100; os dados não são porém conclusivos do mesmo modo, outras alterações fisiológicas podem ser, mais importantes quando representam um afastamento máximo do estado normal;

- pela experiência sexual anterior do indivíduo e a maneira com que foi conciliado por esta experiência;

- pela experiência anterior do indivíduo com determinado parceiro sexual;

- pelas sofisticações obtidas em relação são prolongadas durante longos períodos de anos podem aumentar constantemente, em virtude de maior apreciação das necessidades psicológicas e fisiológicas dos parceiros e de preferência em assuntos sexuais;

- pela novidade da situação sexual, que pode estimular quando velhas situações perderam sua antiga atração:

- pela orientação exclusiva para o organismo e a rapidez com que é atingido. Alguns as preferem atividade ininterrupta, outros preferem práticas demoradas com interrupções deliberadas no sentido de retardar o organismo; (Hite, 1986)

- pelo grau que as atividades sexuais são aceitas psicologicamente.

A presença ou ausência de sentimentos de culpa em muitas pessoas constituem o fator mais importante para determinar o nível de satisfação que podem ser obtidas nas relações sexuais. (Hite, 1986)

Em Dorin (1978) satisfação imaginária é repetida do vocabulário fantasia que seria o processo de associação livre que mão sofre interferência da estimulação externa e que consiste numa deformação catatímica da realidade. Devaneio, imaginação, sonhar acordado (day-dreaming), como mecanismo de defesa do ego, aparece com freqüência nos estados de frustração, acompanhando o isolamento.

Cabral e Nick (1974) referem satisfação como a saciedade plena ou gratificação de um apetite ou, mais genericamente de uma necessidade ou desejo. Estado do organismo quando o objeto necessitado é fornecido de modo tão completo que o apetite ou desejo se extingue em conseqüência da gratificação obtida. Estado de relativa insensibilidade à estimulação que se segue a uma série de estímulos intimamente relacionados:

a) Erótico - relativo às sensações, motivos e sentimentos inspirados pelo impulso sexual com os sentimentos eróticos;

b) Amoroso - relativo à prática amorosa quando o comportamento sexual está envolvido; 
c) Libidinal - relativo as funções do comportamento e a experiência sexual que lhes estiver associados, é termo largamente usado em psicanálise (v. libido);

d) Sensual - relativo a gratificação sexual ou a tendência para a excessiva preocupação com o sexo. (Cabral e Nick, 1974)

"Para a mulher atingir uma satisfação plena, seria preciso que os relacionamentos, fossem uma união de duas existenciais autônomas, não uma abdicação, uma anexação uma fuga, um remédio. Seria necessário que o casal não se considerasse como uma comunidade, e sim que o indivíduo fosse, enquanto indivíduo, integrado numa sociedade no seio da qual pudesse desabrochar sem ajuda; ser-lhe-ia então permitido, dentro de uma generosidade pura, criar laços com outro indivíduo igualmente adaptado a coletividade, laços que teriam fundamentos no reconhecimento de duas liberdades, ou seja, um casal equilibrado, sem procurar no outro a razão exclusiva para viver.- (Beauvoir, 1980)

Em Cuba, Molina e cols. (1994) estudaram os níveis de satisfação pessoal na mulher entre 45 e 59 anos. Obtiveram como resultado de sua pesquisa que a satisfação sexual destas mulheres chega a $32 \%$, e que $60 \%$ delas consideram que os papéis sociais afetam o sexo, e que para $64 \%$ o coito é monótono, mas que $51 \%$ delas tem orgasmos.

Uma pesquisa (Sinal, 1992), parcialmente publicada pela imprensa leiga, com 591 tnulheres de vários estados brasileiros, especialmente São Paulo a Rio, apontou satisfação sexual em $66 \%$ das leitoras daquele periódico voltado ao público feminino.

Considerando o contexto adolescente nas discussões sexuais a da necessidade de descobrir coisas sobre o sexo, e o quanto as discussões apontam apenas para as questões mecânicas e reprodutivas. os autores julgam de importância o estudo da satisfação sexual. Os autores desejando encontrar os sentidos da satisfação sexual para as mulheres adultas procedem à seguinte pesquisa. Outra consideração é a de há muito pouco disponível na literatura específica, no Brasil, sobre a satisfação sexual feminina. Orientamo-nos pela busca da satisfação sexual na mulher, e não dela para o homem ou dos aspectos sociais e do papel sexo-social da mulher.

\section{MATERIAL E MÉTODOS}

Foi feito um estudo piloto com mulheres entre 25 e 40 anos de idade, entregando-se-lhes uma questão única e aberta para que as mesmas a devolvessem respondida: 
- O que é satisfação sexual para você?"

Apenas 8 (oito) questionários foram devolvidos para nós, ou seja $50 \%$ dos mesmos.

Encontramos nos mesmos as seguintes afirmações básicas para a satisfação sexual para mulheres adultas e com parceiros fixos:

1- Sentir atração sexual pelo parceiro:

2- Atingir o orgasmo;

3- Que não basta apenas o ato da penetração que antes de mais nada numa relação a dois deve haver muito carinho;

4- Que o indivíduo antes de mais nada deve estar bem consigo mesmo;

5- E importante que um complete o outro na relação, só assim haverá satisfação sexual:

6- Sexo e fantasias são fundamentais, completa nosso espírito e nossas vidas, centímetro por centímetro;

7- Tudo o que fazemos e sentimos precisa ser recíproco, ou seja deve haver cumplicidade entre parceiros, só assim saem realizados de uma relação sexual;

8- Deve haver desejo entre parceiros, carícias e evidentemente o orgasmo.

\section{SOBRE O QUESTIONÁRIO DESENVOLVIDO A PARTIR DO ESTUDO PILOTO}

Desenvolvemos um questionário com duas questões, sendo que nas mesmas haviam 10 (dez) opções. Entregamos 110 questionários, dos mesmos nos foram entregues 70 questionários preenchidos a apenas 1 (hum) questionário em branco. Todos os questionários foram entregues e respondidos por mulheres desconhecidas e em instituições. Todas as pesquisadas desenvolvem uma atitude profissional fora do Jar, estão na faixa etária entre 25 a 40 anos de idade, são casadas ou com parceria sexual fixa.

\section{PROCEDIMENTO}

Os questionários foram distribuídos em três instituições escolares (uma dessas evangélica. com todas as profissionais dessa instituição 
evangélica). Outra instituição foi a um batalhão de política feminina onde quatorze mulheres responderam o mesmo questionário. E em mais outras duas escolas, 18 (dezoito) professoras do nível 1 e 3 e mais quatro inspetoras de alunos nos responderam o questionário. As 16 (dezesseis) restantes, foram pesquisadas em portas dessas mesmas escolas e nas ruas.

\section{RESULTADOS}

Das 70 mulheres pesquisadas, 18 delas (26\%) afirmaram que para sua satisfação sexual, precisam do ato de penetração sendo que nenhuma delas assinalaram somente este item.

Trinta e cinco mulheres (50\%) precisam usar fantasias sexuais com seu parceiro. Duas mulheres $(2,85 \%)$ precisam ter fantasias sexuais com algum artista. Cinco mulheres pesquisadas $(7,1 \%)$ precisam de fantasias sexuais com desconhecidos. Quatro $(5,7 \%$ a) usam outras fantasias, sendo que nem todas citaram as fantasias usadas; as fantasias citadas eram de sexo a quatro pessoas e fantasias românticas como "Um jantar a luz de velas".

É fundamental sentir-me atraída sexualmente pelo meu parceiro, 52 mulheres $(74,28 \%)$ assinalaram.

Para 43 mulheres $(61,42 \%)$ pesquisadas há a necessidade das carícias do parceiro sexual. Quarenta e seis pesquisadas $(65,71 \%)$ referem que precisam de parceiros carinhosos.

Oito pesquisadas $(11,42 \%)$ precisam de mais coisas que recebem do seu parceiro. "Preciso que passe a mão em todo o corpo e também na vagia" (SIC). "Atenção, carinho, fora da cama também" (SIC). "Dois homens, por exemplo" (SIC). "Sob o meu ponto de vista é muito importante o amor e conhecimento entre os parceiros" (SIC). "De tudo" (SIC). "Valorização como mulher, elogios, etc." (SIC). "Preciso de mais criatividade, coisas novas" (SIC). "De me sentir completamente seduzida pelo parceiro" (SIC).

Para 56 pesquisadas $(80 \%)$ é fundamental atingir o orgasmo.

Sessenta pesquisadas $(85,71 \%)$ sentem-se satisfeitas sexualmente, entretanto 9 das pesquisadas (15\%), ao entregarem o questionário, referiram que nem sempre ficam satisfeitas e que na última questão, poderia ter mais uma opção, "às vezes". Dez mulheres pesquisadas $(14,28 \%)$, não estão satisfeitas sexualmente. 
Uma das pesquisadas falou que para ela uma entrevista seria muito melhor que um questionário, afirmando que gosta muito de falar a respeito e sentiria-se bem mais a vontade sendo entrevistada pessoalmente.

Com outra pesquisada ocorreu o que a princípio fez um comentário que não precisava de fantasias sexuais, entretanto ao ouvir comentários de outras pesquisadas, pediu-me que lhe devolve-se o questionário para que ela fizesse uma retificação no mesmo, colocando então que precisa de fantasias sexuais com seu parceiro e colocou a seguinte observação no questionário: "Eu acredito que a satisfação sexual, além de fantasias, orgasmos ou penetrações, vim de uma convivência diária, de um respeito mútuo que leva como conseqüência o ato de se amar, sinceramente e completamente"(SIC). Devolvendo-me falou o seguinte: "Não adianta algumas mulheres falarem ou escreverem que estão satisfeitas sexualmente, está na cara quando não são" (SIC). Ficando com a face completamente vermelha.

A seguir frases escritas por pesquisadas na folha dos questionários entregues, citando necessidades não satisfeitas em resposta ao item "preciso de mais coisas do que recebo" da questão número 1 :

"Estar satisfeita sexualmente para mim é estar em sintonia plena com o parceiro. “

"Extrapolar a condição do ato em si. Não é simples descarga física, é o encontro pelo carinho pelo prazer, pela vontade de estar realmente com o outro. E dar e receber, é o sentir-se aceita como é. É maravilhoso!"

"Satisfação sexual é quando duas pessoas sentem-se atraídas uma pela outra. Desta atração é óbvio vem o desejo de tocarem-se, a possuírem-se, e quando a atração o desejo é recíproco, e é evidente que virá o orgasmo e assim a satisfação sexual. “

"Quando tudo o que sentimos e, fazemos seja recíproco, pois isso faz com que tenhamos uma satisfação total. E tudo o que acontece em uma relação seja mútua para ambos saírem realizados na sua relação.”

"Me satisfaço sexualmente quando consigo estar inteira dentro de uma relação. Quando o meu corpo, meus sentidos estão todos juntos fazendo com que me sinta feliz e realizada. $O$ orgasmo quando atingido torna tudo maravilhoso, mas para mim, não existe satisfação sexual sem o complemento emocional.

"Sexo para mim é uma coisa normal, que deventos dispor sempre que sentirmos desejo de obter prazer sexual. 
"É o complemento de nossos espíritos, são às nossas fantasias sendo realizadas.

"Vejo como algo necessário e inevitável, pois desejamos estar em sintonia com o parceiro que amamos.

"E penso ser muito importante discutir com nosso parceiro sempre que for necessário o assunto sexualidade. “

"Bom eu entendo que satisfação sexual só é boa quando há compreensão, carinho e amor entre ambos. Então ambos se satisfazem.

"Para atingir a satisfação sexual não basta apenas o ato da penetração, mas que o indivíduo esteja bem consigo mesmo, ou seja, física e psicologicamente. Deve-se contar também que numa relação é fundamental que haja amor e carinho. “

"É você ter atração por alguém que você gosta durante a relação sexual e atingir toda a sua plenitude, ou seja chegar ao auge do orgasmo. Eu acredito que é mais ou menos isso."

\section{OBSERVAÇÕES}

Cinqüenta por cento das mulheres pesquisadas, apesar de fazerem referências a uma satisfação sexual plena, fizeram comentários paralelos à pesquisa. Os comentários referiam-se a estarem satisfeitas sexualmente, mas de forma parcial, que ainda há muito a ser alcançado por elas. Em todas as instituições que fiz esta pesquisa percebi que as mulheres são receptivas, aliás de uma receptividade que me surpreendeu muito. Também percebi que ao me devolverem os questionários preenchidos seus comportamentos estavam um pouco modificados do momento em que foram entregues. As mesmas encontravam-se mais sorridentes. Algumas demoraram mais tempo para devolver, sugerindo que precisaram de um tempo maior para se organizarem e reverem seus conteúdos. Mulheres que nunca vi antes da pesquisa, estão procurando manter uma aproximação comigo após a pesquisa, propondo-me inclusive visitas as suas residências. Poucas foram as mulheres que sentiram-se constrangidas ao devolver-me o questionário e algumas mostraratn-se curiosas com os resultados dessa pesquisa. Percebi nesta pesquisa que a maior parte das mulheres gostam de falar sobre este assunto.

Apenas na instituição educacional evangélica todas as 20 professoras que receberam o questionário os devolveram respondidos. 


\section{DISCUSSÃO}

A partir do que pesquisamos teoricamente e dos 50 (cinqüenta) questionários que foram devolvidos, houveram algumas discrepâncias. Pudemos observar que apesar das $85,71 \%$ das mulheres afirmarem uma satisfação sexual plena. Muitas mulheres falaram da necessidade de uma maior igualdade de mais carícias de maiores fantasias que estão sendo supridas pelo parceiro. Ainda sentem-se reprimidas no relacionamento e nos falaram que na segunda questão que fala sobre o orgasmo precisaria de mais uma opção paralela ao sim e não.

\section{CONCLUSÕES}

As mulheres esperam mais dos seus homens atualmente, a maioria das mulheres não se sente mais uma propriedade, buscam sua satisfação, seja com fantasias sexuais, carícias e não apenas o ato da penetração. A mulher leva um tempo maior para excitar-se, e para que isso possa ocorrer com as mesmas, esperam que seja por alguém que fundamentalmente as atraia sexualmente, que seja carinhoso e compreensivo, que as ame, não desejando mais serem vistas como meros objetos para a satisfação sexual masculina. Esperam que eles também possam ser o objeto do desejo delas e para isso acontecer pedem mais, exigem o orgasmo, afinal isso é uma vitória conquistada pela mulher dos tempos modernos. Estão mais liberais com o tema sexualidade e sentem-se mais liberais na cama com seus homens. $\mathrm{O}$ ato da penetração por si só quer dizer muito pouco para a mulher adulta, é apenas um complemento de um ato de amor, que para elas é fundamental "o amor".

Nessa pesquisa pode-se constatar, que a mulher adulta na metrópole paulistana, para atingir a satisfação sexual plena, depende muito da satisfação como indivíduo, que para a mulher é fundamental o relacionamento e a preservação do namoro, da sedução e das carícias envolventes do parceiro. A mulher precisa estar atraída pelo parceiro e sentir que o atrai. $\mathrm{O}$ sexo pelo sexo não parece ser a busca da maioria das mulheres. A satisfação sexual precisa estar cercada de carícias e de parceiros carinhosos. Mais de um décimo das pesquisadas conhecem o caminho pelo qual os parceiros deveriam buscar facilitar a satisfação sexual delas. Muitas mulheres não tem nem consciência do que necessitam para a própria satisfação sexual. Outras podem não conseguir expressar-se adequadamente e eficaz- 
mente aos seus parceiros, ou sequer para uma pesquisa sobre a satisfação sexual. Lerer (1992) afirma que a mulher pode negar a si mesma as necessidades e vontades e relutar em partilhar-se com seu parceiro.

Apenas pouco mais de um quarto das mulheres afirmaram a preferência sexual igual à do discurso sexual masculino em nossa cultura. A penetração, tão fortalecida e valorizada pelo homem no contexto sexual é deixada de lado pela maioria das mulheres. Esta não é uma informação assimilada pelo homem, muito pelo contrário, as informações que os homens trocam entre si e recebem advindas através de revistas eróticas e filmes pornográficos (facilmente constatável pelo leitor) valorizam direta e explicitamente a penetração no ato sexual. A maioria (80\%) declarou que necessita do orgasmo na relação sexual (Molina e cols. - 1994 - apontam que $51 \%$ das mulheres cubanas tem orgasmos nas relações sexuais).

A fantasia sexual para a mulher adulta é usada como forma de estimulação sexual e voltada para o próprio parceiro, o que deveria ser considerado pelos homens, para que não julgassem que o uso de fantasias implicaria em possibilidade e motivação de traição sexual.

Embora costumeiramente as mulheres serem consideradas mais para fantasias românticas do que o homem, nesta pesquisa estas buscas não foram referidas, talvez pela dificuldade em expressar a intimidade que é a própria fantasia.

Para a mulher a sexualidade não começa na cama, tampouco termina, a sexualidade é o cotidiano com seu parceiro e tudo aquilo que ela possa demonstrar de afetividade.

Embora possamos contestar que o discurso das entrevistas possa ser equivocado enquanto realidade objetiva, devemos considerar os resultados e conclusões como representantes do social, não necessariamente do que vivem estas pessoas, mas do que elas desejam que seja considerado com parte integrante de suas identidades femininas nesta cultura. Estes parâmetros são os que devem ser utilizados para os profissionais que trabalham com esta população e sobre este assunto. As representações sociais apresentadas pelas pesquisadas constituemse cognições que aquelas utilizam para se relacionar com a realidade concreta, fatos de importância para o se trabalhar como ser humano.

Concluímos com a presente pesquisa que $86 \%$ das mulheres pesquisadas sentem-se satisfeitas sexualmente. Molina e cols. (1994) referem em pesquisa sobre satisfação sexual de mulheres cubanas que estas se consideram satisfeitas apenas em 32\%, aumentando para, se somarmos aquelas que se sentem mais ou menos satisfeitas, $65 \%$, valores menores que o 
encontrado nesta pesquisa". A insatisfação sexual, porém existe num número de importância entre mulheres (14\%), que merece atenção dos profissionais que trabalham com saúde mental.

\section{REFERÊNCIAS BIBLIOGRÁFICAS}

1. BEAUVOIR, S. (1980). O segundo sexo, vol. 2: a experiência vivida. Rio de Janeiro. Editora Nova Fronteira, $2^{a}$ edição.

2. BRASIL NOVO (edit.) (1979). Grande dicionário enciclopédio brasileiro ilustrado. Rio de Janeiro, São Paulo, Editora Brasil Novo.

3. BROWN, F. R. (1963). Sexo: perguntas e respostas. São Paulo, Editora Cultrix. $2^{\mathrm{a}}$ edição.

4. CABRAL. A.: NICK, E. (1974). Dicionário técnico de psicologia. São Paulo, Ed. Cultrix.

5. DORIN, E. outros (1978). Dicionário de psicologia, abrangendo terminologia de ciências correlatos. São Paulo, Editora Melhoramentos.

6. FERNANDES, F. (1970). Dicionário brasileiro contemporâneo. Porto Alegre, Ed. Globo, $2^{\text {a }}$ edição,

7. HITS, S. (1986). Relatório Hite. Rio de Janeiro, Civilização Brasileira, $4^{\mathrm{a}}$ edição.

8. LERER, M. L. (1992). Hacer-se mujer. Buenos Aires, Beas Ediciones.

9. MOLINA, O.; ALONSO RODRIGUEZ, R. y cols. (1994). Influência de la inadecuada da conducta sexual en los niveles de satifacción personal em la mujer de edade mediana. Anais do VII Congresso Latinoamericano de Sexologia y Educación Sexual, La Habana.

10. SINAL PESQUISAS DE PSICOLOGIA DO CONSUMO LTDA. (1992). Pesquisa sobre sexo - Revista Elle. São Paulo. material mecanografado.

1. Obviamente não podemos comparar, pura e simplesmente as duas amostras. A amostra brasileira é de classe trabalhadora e média, mas que vivem em condições cotidianas superiores à amostra cubana, esta provavelmente de nível intelectual mais elevado (21\% com $3^{\circ}$ grau completo). 


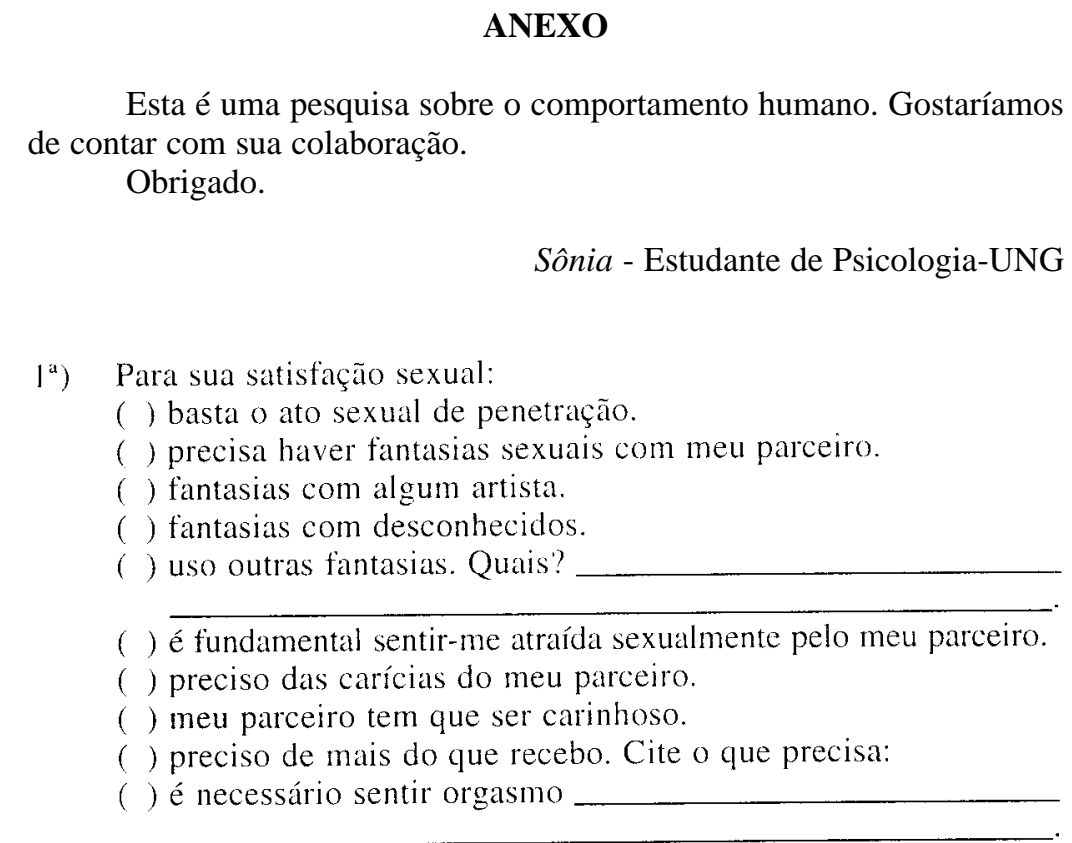

$\left.2^{a}\right)$ Você se considera satisfeita sexualmente?

( ) $\operatorname{sim}$ ( ) não. 